\title{
Performance Evaluation of New Ranking Function Methods with Current Ranking Functions Using VAM and MM-VAM
}

\author{
Fahrudin Muhtarulloh ${ }^{1, *}$ Atia Nuraini ${ }^{2}$ \\ ${ }^{1}$ Department Mathematics, UIN Sunan Gunung Djati Bandung, Bandung, Indonesia \\ ${ }^{2}$ Department Mathematics, UIN Sunan Gunung Djati Bandung, Bandung, Indonesia \\ ${ }^{*}$ Corresponding author. Email: fahrudin.math@uinsgd.ac.id
}

\begin{abstract}
This paper discusses the optimal solution for specific types of optimization problems called fuzzy transportation problems using pentagonal fuzzy numbers. Cost value, supply, and the demand for fuzzy transport issues are taken as fuzzy numbers pentagonal. Pentagonal fuzzy numbers are converted to crisp values using functions recommended for new rankings. The purpose of this study is to compare new ranking methods with old rankings as well as Vogel's Approximation Method (VAM) and Max Min Voge'l Approximation Method (MM-VAM) in finding optimal solutions to fuzzy transportation problems. From the results of the study, it was obtained that the new ranking method with VAM method gets the smallest transportation cost. Press Proceedings article template has many predefined paragraph styles for you to use/apply as you write your paper. To format your abstract, use the Microsoft Word template style: [Abstract]. Each paper must include an abstract. Begin the abstract with the title "Abstract" in bold font, followed by a paragraph with normal 10-point font. Do not cite references in the abstract. Please do not place or cite tables and figures in the abstract either.
\end{abstract}

Keywords: Fuzzy Transportation, Pentagonal Fuzzy Number, New Ranking Function, Max-Min Vogel's Approximation Method.

\section{INTRODUCTION}

The Operation research is an effort related to scientific decision makers by determining an appropriate model in running a system that through limited resource allocation to get optimum results [1]. Operation research deals with transportation issues that use a mathematical model as part of a problem-solving solution to get optimum results. Transportation problems are the problem of distributing goods from multiple supplies (sources) to multiple requests (destinations) with the intention of minimizing transportation costs [2].

Transportation problems are special kinds of problems in optimization. They are associated with realworld activities that are managed with logistics. The problem for transportation includes transportation with a single manufacturing product in different supplies to a number of different destinations [3]. Uncertainty in demand, inventories, and shipping costs has caused fuzzy transportation problems. Transportation problems are a common problem in life, fuzzy transportation problems are transportation problems with the parameters of demand, supply, Cost or variable are fuzzy numbers [2]. The authors in [3], [4], [5], [6] studied fuzzy transportation problems depending on the ranking function to find the optimal solution. The method of solving transportation problems is progressing, one of the methods of completion is Vogel Approximation Method (VAM) and Max-Min Vogel Approximation Method (MM-VAM).

Previous research related to fuzzy transportation problems using existing ranking formulas resulted in optimum solutions that can still be fixed. In existing roles it involves a combination of pentagonal fuzzy numbers divided by the number 4 . While the new role formula involving a combination of pentagonal fuzzy numbers is divided by a number greater than the number 4 . This is thought to further minimize transportation costs so as to improve the optimum solution beforehand. This is why the authors are interested in discussing optimal algorithms for fuzzy transport issues. 


\section{METHOD}

\subsection{Problems of Fuzzy Transport}

Transportation problems with the number of supplies, the amount of demand, and the cost of transportation are expressed by fuzzy numbers. The purpose of transportation problems is to determine the optimal amount of goods transported from various sources to various destinations so that the total transportation cost is minimum [3]. Problems in fuzzy transport can be written as follows:

Minimize $\tilde{z}=\sum_{\mathrm{s}=1}^{\mathrm{m}} \sum_{\mathrm{t}=1}^{\mathrm{n}} \widetilde{\mathrm{c}_{\mathrm{st}}} \widetilde{\mathrm{x}_{\mathrm{st}}}$

Subject to:

$$
\begin{aligned}
& \sum_{\mathrm{t}}^{\mathrm{n}} \widetilde{\mathrm{x}_{\mathrm{st}}}=\widetilde{\beta_{\mathrm{s}}}, \mathrm{s}=1,2, \ldots, \mathrm{m} \\
& \sum_{\mathrm{s}=1}^{\mathrm{m}} \widetilde{\mathrm{x}_{\mathrm{st}}}=\overline{\delta_{\mathrm{t}}}, \mathrm{t}=1,2, \ldots, \mathrm{n} \\
& \sum_{\mathrm{s}=1}^{\mathrm{m}} \bar{\beta}_{1}=\sum_{\mathrm{t}=1}^{\mathrm{m}} \bar{\delta}_{\mathrm{t}}, \widetilde{\mathrm{x}_{\mathrm{st}}} \geq 0,
\end{aligned}
$$

For all $\mathrm{s}$ and $\mathrm{t}$

Where:

$\widetilde{\beta}_{\mathrm{s}}=$ fuzzy accessibility at $\mathrm{s}^{\text {th }}$ source

$\tilde{\delta}_{\mathrm{t}}=$ fuzzy demand at $\mathrm{t}^{\text {th }}$ destination

$\tilde{\mathrm{c}}_{\mathrm{st}}=$ fuzzy transportation codt from source to destination $\tilde{\mathrm{x}}_{\text {st }}=$ number of fuzzy units carries over from source to destination

\subsection{Fuzzy numbers [6]}

Assume that $B$ is a standard set and $\mathrm{MB}(\mathrm{X})$ is a function from $B$ to the interval [0.1]. The fuzzy set of $B$ with $\mathrm{MB}(\mathrm{X})$ membership functions is represented by $\mathrm{B}=$ $\{\mathrm{x}, \mathrm{MB}(\mathrm{X}) ; \mathrm{x} \varepsilon \mathrm{B}$ and $\mathrm{MB}(\mathrm{X}) \varepsilon[0,1]\}$.

\subsubsection{Fuzzy Pentagonal Numbers [7]}

The pentagon fuzzy number $\overline{B p}=(\delta, \beta, \mathrm{c}, \mathrm{d}, \mathrm{e})$ where $\delta, \beta, \mathrm{c}, \mathrm{d}$, and e are real seedlings and $\beta \leq \delta \leq \mathrm{c} \leq \mathrm{d} \leq \mathrm{e}$ with membership functions obtained below:

$$
M_{B}(X)=\left\{\begin{array}{cr}
L_{1}(x)=\frac{(x-\beta)}{(\delta-\beta)} & \text { for } \beta \leq x \leq \delta \\
L_{2}(x)=\frac{(x-\delta)}{(c-\delta)} & \text { for } \delta \leq x \leq c \\
1 & \text { for } x=c \\
R_{1}(x)=\frac{(x-\beta)}{(\delta-\beta)} & \text { for } c \leq x \leq d \\
R_{2}(x)=\frac{(x-\beta)}{(\delta-\beta)} & \text { for } d \leq x \leq e \\
0 & \text { otherwise }
\end{array}\right.
$$

\subsection{Ranking Function [8]}

Fuzzy transport problems depend on the rating function to find the optimal solution. In ranking function decision-making is very important, the optimal solution of fuzzy transport problems uses total integral rating function values and fuzzy numbers. Here is the ranking function used on this fuzzy transport issue.

\subsubsection{Current Ranking Function}

Fuzzy numbers are based on the R: R (F) function $\rightarrow R$. The fuzzy set of numbers presents a set of real numbers, which maps each fuzzy number to a real number. The rank function of pentagonal fuzzy number:

$\mathrm{R}\left(\bar{B}_{\mathrm{p}}\right)=\frac{1}{4}(2 \beta+3 \delta+2 c+3 d+2 e)$

\subsubsection{New Ranking Function [3]}

A new solution of fuzzy transport problems with integer interval form, i.e. $\alpha$-cut dari $\widetilde{\mathrm{B}}=(\beta, \delta, \mathrm{c}, \mathrm{d}, \mathrm{e}), 0 \leq \alpha \leq 1$ is

$\mathrm{B}(\alpha)=\left[\mathrm{B}_{\mathrm{L}}(\alpha), \mathrm{B}_{\mathrm{R}}(\alpha)\right]$

$\frac{x-\beta}{\delta-\beta}=\alpha \rightarrow x=\beta+\alpha(\delta-\beta)$

$\mathrm{B}_{\mathrm{L} 1}(\alpha)=\beta+\alpha(\delta-\beta)=\mathrm{L}_{1}^{-1}(\alpha)$

$\frac{\mathrm{x}-\delta}{\mathrm{c}-\delta}=\alpha \rightarrow \mathrm{x}=\delta+\alpha(\mathrm{c}-\delta)$

$\mathrm{B}_{\mathrm{L} 2}(\alpha)=\delta+\alpha(\mathrm{c}-\delta)=\mathrm{L}_{2}^{-1}(\alpha)$

and

$\frac{d-x}{d-c}=\alpha \rightarrow x=d-\alpha d+\alpha c$

$B_{R 1}(\alpha)=d-\alpha d+\alpha c=R_{1}^{-1}(\alpha)$

$\frac{e-x}{e-d}=\alpha \rightarrow x=e-\alpha e+\alpha d$

$\mathrm{B}_{\mathrm{R} 2}(\alpha)=\mathrm{e}-\alpha \mathrm{e}+\alpha \mathrm{d}=\mathrm{R}_{2}^{-1}(\alpha)$

so

$\mathrm{L}^{-1}(\alpha)=\frac{\mathrm{L}_{1}^{-1}(\alpha)+\mathrm{R}_{2}^{-1}(\alpha)}{2}$

$\mathrm{R}^{-1}(\alpha)=\frac{\mathrm{R}_{1}^{-1}(\alpha)+\mathrm{R}_{2}^{-1}(\alpha)}{2}$

By using the following ranking function

$\mathrm{R}\left(\overline{\mathrm{B}}_{\mathrm{p}}\right)=\frac{\int_{0}^{\mathrm{w}} \mathrm{y}^{5}\left[\frac{\mathrm{L}^{-1}(\alpha)}{2}+\frac{\mathrm{R}^{-1}(\alpha)}{2}\right] \mathrm{d} \alpha}{\int_{0}^{\mathrm{w}} \mathrm{y}^{5} \mathrm{~d} \alpha}$

with $0 \leq \alpha \leq$ w and $\mathrm{w} \leq \alpha \leq 1$

$$
\begin{aligned}
& \mathrm{R}\left(\overline{\mathrm{B}}_{\mathrm{p}}\right)=\frac{1}{2}\left[\frac{\int_{0}^{1} \beta^{5}\left[\frac{\beta+\delta+\delta(\mathrm{c}-\delta)}{2}+\frac{\mathrm{d}+\mathrm{e}-\beta(\mathrm{e}-\mathrm{c})}{2}\right] \mathrm{d} \alpha}{\int_{0}^{1} \beta^{5} \mathrm{~d} \alpha}\right] \\
& \mathrm{R}\left(\overline{\mathrm{B}}_{\mathrm{p}}\right)=\left[\frac{\delta+7 \delta+12 \mathrm{c}+7 \mathrm{~d}+\mathrm{e}}{28}\right]
\end{aligned}
$$




\subsection{Algorithm for Solving a Fuzzy Transportation Problem with New Ranking Function [3],}

The precursors in resolving fuzzy transportation problems according as follows:

- Change the cost, supply, and demand values of fuzzy transportation issues, all of which are pentagonal fuzzy numbers, to sharp values using the proposed rankings.

- Check the balance condition to make sure the total demand is equal to the total supply.

- Get the optimal solution with the VAM and Max-Min VAM method.

- Reduce the cost of cells in a column (row) which has the lowest value of the next cell cost in the same row (column) to calculate the penalty cost for all rows and columns.

- Select the largest penalty charge from the column (row).

- Make use of cells with the lowest transport cost on rows or columns with the highest penalty charges.

- Determine the total transportation cost of a decent allocation.

- Specify the total minimum cost of the product.

\subsection{Vogel's Approximation Method (VAM) [9]}

VAM is a heuristic solution model and usually results in a more initial solution than other methods (North West and the smallest cost). But in reality, the solution VAM is not necessarily an optimal solution. As for the measures VAM method is as follows [10]:

- Calculate the penalty of each row and column. The penalty score is derived from the difference between the smallest of rows or columns with the second smallest value of the same row or column.

- Select the largest Penalty.

- Allocate as many items as possible to cells at the smallest cost.

- Stop the process when all goods have been allocated and all requests have been filled. If you haven't already,

- Repeat step 1 with the condition that rows/columns with the number of items 0 do not participate calculated in the next iteration.

VAM typically produces optimal or near-optimal value by accuracy rate up to $80 \%$.

\subsection{Max-Min Vogel's Approximation Method [9]}

VAM has many gaps in the steps so that it can produce optimal value (achieves a minimum fee). Therefore, a VAM modification method is proposed, namely Max-Min Vogel's Approximation Method (MMVAM) to perfect VAM working steps. Max-Min Vogel's proposed Approximation Method (MM-VAM) can be produce a more optimal value than VAM, as it modifies some of the existing steps in VAM. The modifications made are: first is to look for total opportunity cost (TOC) matrix, subsequently seeking penalties by reducing the between the largest cost (Max) and the smallest cost (Min), then select the two largest penalise and lastly use minimal (cost $\mathrm{X}$ allocation) to select cells.

\subsubsection{Max-Min VAM Algorithm (MM-VAM)}

The method proposed in this study is called Max-Min Vogel's Approximation Method (MM-VAM) and is a modification of the basic VAM. Max-Min Vogel's. The proposed Approximation Method (MM-VAM) can produce more value optimal than VAM because it modifies some of the existing steps in VAM. A method this modification is a heuristic method and involves a matrix of Total Opportunity Cost (TOC). Matrix TOC obtained from summing between Opportunity Cost (OC) line and OC Column. OC line is the matrix value obtained from the subtraction of each row with the smallest value of the row. While the OC column is the matrix value derived from the subtraction of each column with the smallest value of that column. After obtained by Matrix TOC, the next to seek a penalty by reducing the cost of

(Max) at the smallest cost (Min), then select the two largest and last penalties use a minimum (cost $\mathrm{X}$ allocation) to select a cell. The details of the MM-VAM algorithm steps are as follows:

- Calculate the penalty of each row and column. Penalty rates are derived from deductions maximum value with a minimum value of each row and column.

- Choose the two highest penalties. If there is the same penalty value, select all.

- Find the cell with the smallest cost on each penalty.

- Allocate as many items as possible to the cell.

- Between the selected cells, select a cell that has a transport value (cost $\mathrm{x}$ allocation) is smallest.

a. If there is the same transport value, select the smallest cost.

b. If the smallest cost is the same, then select the highest allocation.

c. If the highest allocation is the same, select the highest penalty value.

- Stop the process when all goods have been allocated and all requests have been filled. If you haven't already,

- Repeat step 1 with the condition that rows/columns with the number of items 0 do not participate calculated in the next iteration. 


\section{NUMERICAL ILLUSTRATIONS}

\subsection{Case 1}

Fuzzy pentagonal transportation problems from three $\mathrm{s}_{1}, \mathrm{~s}_{2}, \mathrm{~s}_{3}$ and destinations $\mathrm{DE}_{1}, \mathrm{DE}_{2}, \mathrm{DE}_{3}$. The value of the cost of transporting from source $\mathrm{i}$ to destination $\mathrm{j}$, which is a pentagonal fuzzy number, is listed in table 1 .

Table 1. Pentagonal fuzzy transport table

\begin{tabular}{lllll}
\hline \multirow{5}{*}{$\begin{array}{l}\text { Sour } \\
\text { ces }\end{array}$} & \multicolumn{4}{c}{$\begin{array}{l}\text { Destina } \\
\text { tion }\end{array}$} \\
\cline { 2 - 4 } & \multicolumn{5}{c}{$\mathrm{DE}_{1}$} & \multicolumn{1}{c}{$\mathrm{DE}_{2}$} & \multicolumn{1}{c}{$\mathrm{DE}_{3}$} & Supply \\
\hline $\mathrm{s}_{1}$ & $(1,3,4$ & $(0,2,3$, & $(2,4,5,6,8$ & $(4,6,7,8,1$ \\
& $, 5,7)$ & $4,6)$ & ) & $0)$ \\
$\mathrm{s}_{2}$ & $(3,5,6$ & $(5,7,8$, & $(4,6,7,8,1$ & $(6,8,9,10$, \\
& $, 7,9)$ & $9,11)$ & $0)$ & $12)$ \\
$\mathrm{s}_{3}$ & $(1,3,4$ & $(2,4,5$, & $(3,5,6,7,9$ & $(10,12,13$, \\
& $, 5,7)$ & $6,8)$ & ) & $14,16)$ \\
Dem & $(3,5,6$ & $(5,7,8$, & $(12,14,15$, & \\
and & $, 7,9)$ & $9,11)$ & $16,18)$ & \\
\hline & & & & \\
\hline
\end{tabular}

From table 1, number of supply $=[20,26,29,32,38]$ and number of demand $=[20,26,29,32,38]$. It appears that the balance condition is met.

\subsubsection{New ranking function:}

Apply all values with the new rank function.

$$
\mathrm{R}\left(\overline{\mathrm{B}}_{\mathrm{p}}\right) \quad=\left[\frac{\delta+7 \delta+12 \mathrm{c}+7 \mathrm{~d}+\mathrm{e}}{28}\right]
$$

After applying all values with the new ranking function generates table 2 as follows:

Table 2. Subtracted from new ranking function

\begin{tabular}{lrrrr}
\hline & \multicolumn{4}{c}{ Destination } \\
\cline { 2 - 4 } Sources & $\mathrm{DE}_{1}$ & $\mathrm{DE}_{2}$ & $\mathrm{DE}_{3}$ & Supply \\
\hline $\mathrm{s}_{1}$ & 4 & 3 & 5 & 7 \\
$\mathrm{~s}_{2}$ & 6 & 8 & 7 & 9 \\
$\mathrm{~s}_{3}$ & 4 & 5 & 6 & 13 \\
Demand & 6 & 8 & 15 & \\
\hline
\end{tabular}

- Vogel's Approximation Method

Once all the desired allocations for each request are obtained, the calculation of the cost singed from the initial matrix. Complete final VAM and the allocation that has been decided by the system is shown in Table 3 .
Table 3. Solution Final VAM

Destination

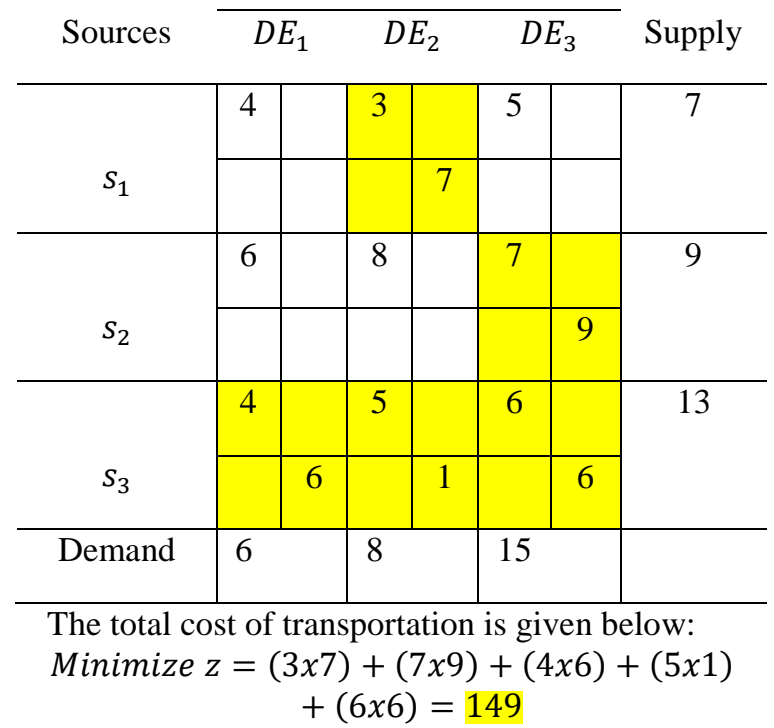

- Max-Min Vogel's Approximation Method (MM-VAM)

Allocate so that the demand and goals are met according to the source and supply by using Max-Min VAM. The matrix studied in this study is shown in table 2. Calculation results $\mathrm{OC}$ row and the calculation result of the OC Column. While the TOC matrix is shown in table 4.

Table 4. TOC Matrix

\begin{tabular}{cccc}
\hline & \multicolumn{3}{c}{ Destinations } \\
\cline { 2 - 4 } Sources & $\mathrm{DE}_{1}$ & $\mathrm{DE}_{2}$ & $\mathrm{DE}_{3}$ \\
\hline $\mathrm{s}_{1}$ & 1 & 0 & 2 \\
$\mathrm{~s}_{2}$ & 2 & 7 & 3 \\
$\mathrm{~s}_{3}$ & 0 & 3 & 3 \\
\hline
\end{tabular}

The MM-VAM process is carried out with steps as described in the in the previous chapter that each iteration continues to repeat. Each iteration is performed calculation of penalties and decision-making for the placement of goods or supplies asked. Once all the desired allocations for each request are obtained, the calculation of the cost singed from the initial matrix. Complete final MM-VAM matrix and the allocation that has been decided by the system is shown in table 5 . 
Table 5. Solution Final MM-VAM Matrix

\section{Destination}

\begin{tabular}{|c|c|c|c|c|c|c|c|}
\hline Sources & \multicolumn{2}{|c|}{$D E_{1}$} & \multicolumn{2}{|c|}{$D E_{2}$} & \multicolumn{2}{|c|}{$D E_{3}$} & Supply \\
\hline \multirow[b]{2}{*}{$S_{1}$} & 4 & & 3 & & 5 & & \multirow[t]{2}{*}{7} \\
\hline & & & & 7 & & & \\
\hline \multirow[b]{2}{*}{$s_{2}$} & 6 & & 8 & & 7 & & \multirow[t]{2}{*}{9} \\
\hline & & 6 & & & & 3 & \\
\hline \multirow[b]{2}{*}{$S_{3}$} & 4 & & 5 & & 6 & & \multirow[t]{2}{*}{13} \\
\hline & & & & 1 & & 12 & \\
\hline Demand & 6 & & 8 & & 15 & & \\
\hline
\end{tabular}

The total cost of transportation is given below:

$$
\begin{aligned}
\text { Minimize } z= & (3 \times 7)+(6 \times 6)+(7 \times 3) \\
& +(5 \times 1)+(6 \times 12)=155
\end{aligned}
$$

\subsubsection{Current Ranking function:}

Apply it by using the current rank function of the pentagonal number to calculate the cost of transportation.

$$
\mathrm{R}\left(\bar{B}_{\mathrm{p}}\right)=\frac{1}{4}(2 \beta+3 \delta+2 c+3 d+2 e)
$$

After applying all values with the current ranking function generates table 6 as follows.

Table 6. The table is subtracted from the existing ranking function.

\begin{tabular}{lcccc}
\hline & \multicolumn{4}{c}{ Destination } \\
\cline { 2 - 4 } Sources & $\mathrm{DE}_{1}$ & $\mathrm{DE}_{2}$ & $\mathrm{DE}_{3}$ & Supply \\
\hline $\mathrm{s}_{1}$ & 12 & 9 & 15 & 21 \\
$\mathrm{~s}_{2}$ & 18 & 24 & 21 & 27 \\
$\mathrm{~s}_{3}$ & 12 & 15 & 18 & 39 \\
& & & & \\
Demand & 18 & 24 & 45 & \\
\hline
\end{tabular}

\section{- Vogel's Approximation Method}

Once all the desired allocations for each request are obtained, the calculation of the cost singed from the initial matrix. Complete final VAM and the allocation that has been decided by the system is shown in Table 7 .
Tabel 7. Solution Final VAM.

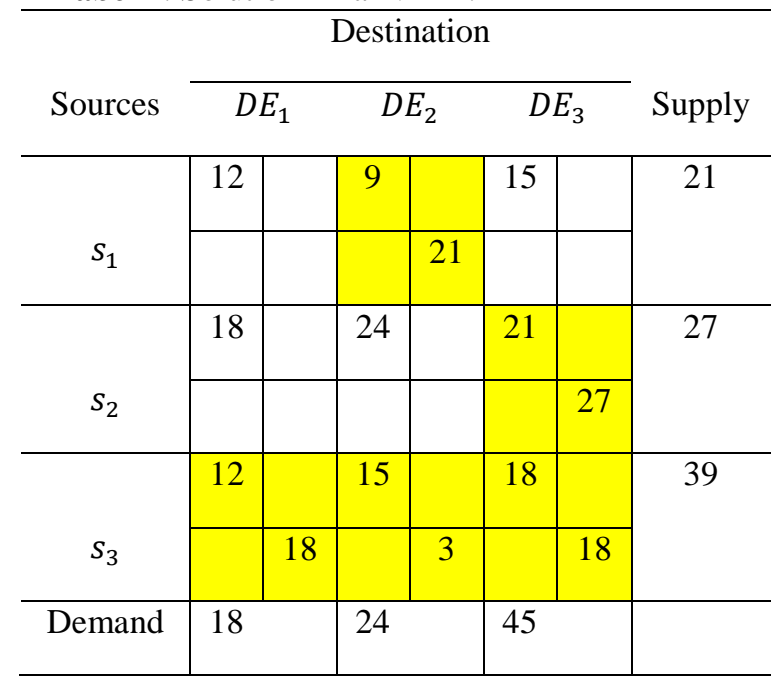

The total cost of transportation is given below:

Minimize $\mathrm{z}=(9 \times 21+21 \times 27+12 \times 18+15 \times$

$3+18 \times 18)$

$$
\begin{aligned}
& =(189+567+216+45+324) \\
& =1341
\end{aligned}
$$

Max-Min Vogel's Approximation Method (MMVAM)

Once all the desired allocations for each request are obtained, the calculation of the cost singed from the initial matrix. Complete final matrix and the allocation that has been decided by the system is shown in Table 8 .

Table 8. Solution Final MM-VAM Matrix Destination

\begin{tabular}{c|c|c|c|c|c|c|c}
\cline { 2 - 6 } Sources & \multicolumn{2}{c}{$D E_{1}$} & \multicolumn{2}{c}{$D E_{2}$} & \multicolumn{2}{c}{$D E_{3}$} & \multicolumn{1}{c}{ Supply } \\
\multirow{3}{*}{$s_{1}$} & 12 & & 9 & & 15 & & 21 \\
\cline { 2 - 7 } & & & & 21 & & & \\
\hline \multirow{3}{*}{$s_{2}$} & 18 & & 24 & & 21 & & 27 \\
\cline { 2 - 6 } & & 18 & & 3 & & 6 & \\
\hline \multirow{3}{*}{$s_{3}$} & 12 & & 15 & & 18 & & 39 \\
\cline { 2 - 6 } & & & & & & 39 & \\
\hline Demand & 18 & & 24 & 45 & & \\
\hline
\end{tabular}

The total cost of transportation is given below: minimize $z=(9 \times 21)+(18 \times 18)+(24 \times 3)+(21 \times 6)$ $+(18 \times 39)=1413$ 


\subsection{Case 2}

Fuzzy pentagonal transportation problems from three sources $\mathrm{s}_{1}, \mathrm{~s}_{2}, \mathrm{~s}_{3}$ and destinations $\mathrm{DE}_{1}, \mathrm{DE}_{2}, \mathrm{DE}_{3}$. The value of the cost of transporting from source $i$ to destination $\mathrm{j}$, which is a pentagonal fuzzy number, is listed in table 9.

Table 9. Pentagonal fuzzy transport table

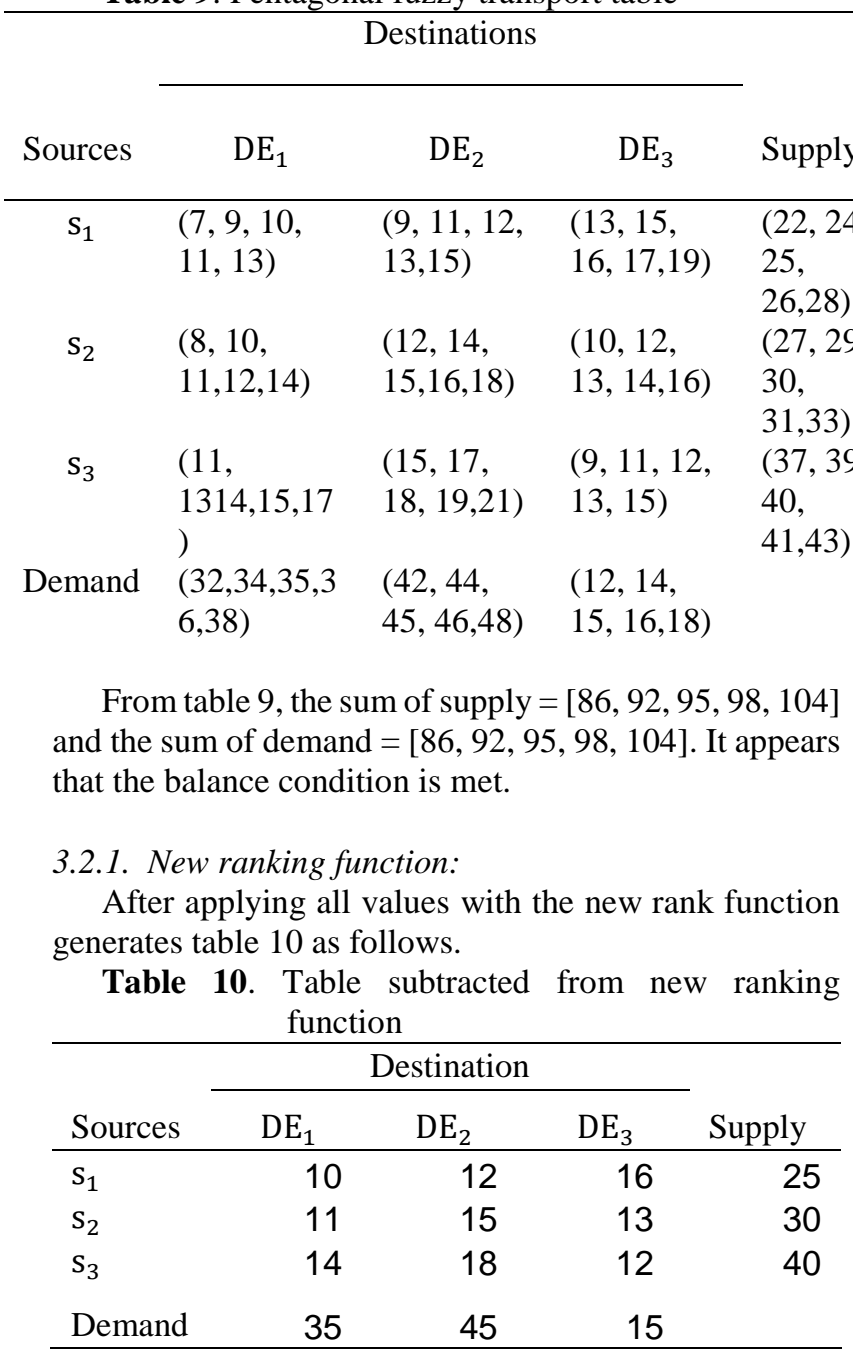

- Vogel's Approximation Method

Complete final VAM and the allocation that has been decided by the system. Total cost of transportation is given below:

Minimize $\mathrm{z}=(12 \times 25+11 \times 30+14 \times 5+18 \times$ $20+12 \times 15)$

$$
\begin{aligned}
& =(300+330+70+360+180) \\
& =1240
\end{aligned}
$$

- Max-Min Vogel's Approximation Method (MM-VAM)

Complete final matrix and the allocation that has been decided by the system. Total cost of transportation is given below:

$$
\begin{aligned}
\text { Minimize } z= & (10 \times 25)+(11 \times 10)+(15 \times 20) \\
& +(18 \times 25)+(12 \times 15)=1290
\end{aligned}
$$

\subsubsection{Current Ranking Function}

After applying all values with the current ranking function generates table 11 as follows.

Table 11. The table is subtracted from the existing ranking function.

Destination

\begin{tabular}{lrrrl} 
Sources & $\mathrm{DE}_{1}$ & $\mathrm{DE}_{2}$ & $\mathrm{DE}_{3}$ & Supply \\
\hline $\mathrm{s}_{1}$ & 30 & 36 & 48 & 75 \\
$\mathrm{~s}_{2}$ & 33 & 45 & 39 & 90 \\
$\mathrm{~s}_{3}$ & 42 & 54 & 36 & 120 \\
Demand & 105 & 135 & 45 & \\
\hline
\end{tabular}

- Vogel's Approximation Method

Complete final VAM and the allocation that has been decided by the system. Total cost of transportation is given below:

$$
\begin{aligned}
\text { Minimize } z= & (36 \times 75+33 \times 90+42 \times 15+ \\
54 \times 60+36 \times 45) & \\
= & (2700+2970+630+3240+1620) \\
= & 11160
\end{aligned}
$$

- Max-Min Vogel's Approximation Method (MM-VAM)

Complete final matrix and the allocation that has been decided by the system. Total cost of transportation is given below:

$$
\begin{aligned}
\text { minimize } z= & (30 \times 75)+(33 \times 30)+(45 \times 60) \\
& +(54 \times 75)+(36 \times 45)=11610
\end{aligned}
$$

Styles can be applied using the style palette available within the template. To activate it the press Ctrl+Shift+s. Apply the style as required based on the content and context. (Please don't highlight your text in yellow.)

\section{CONCLUSIONS}

Comparison of the total transportation cost of the new ranking function and the current ranking function with VAM and MM-VAM is shown table 12.

Table 12. Comparison table.

$\begin{array}{cc}\text { New Ranking } & \text { Current Ranking } \\ \text { Function } & \text { Function }\end{array}$

\begin{tabular}{ccccc}
\cline { 2 - 5 } Case & VAM & $\begin{array}{c}\text { MM- } \\
\text { VAM }\end{array}$ & VAM & $\begin{array}{l}\text { MM- } \\
\text { VAM }\end{array}$ \\
\hline Case 1 & 149 & 155 & 1341 & 1413 \\
Case 2 & 1240 & 1290 & 11160 & 11610 \\
\hline
\end{tabular}


The study considered several examples of fuzzy transport with the value of the cost obtained as a pentagonal fuzzy number. This is converted to a sharp value using the proposed rating function. Optimal solutions are obtained through VAM. The proposed new rating function proved more capable than the current rating function to get the optimal solution for the total minimum transportation cost. Similarly, VAM proved to be more capable than MM-VAM in both cases.

\section{REFERENCES}

[1] Hermawan H et al 2019 Riset Operasi (Tangerang Selatan: Unpam Press) p 45

[2] Solikhin 2019 Metode Cost Derivation pada Masalah Transfortasi Fuzzy Segitiga Simetri dengan Robust Ranking dan Mean Parameter (Proceedings of the National Seminar on Mathematics vol 2) pp 268-276

[3] R. J. Mitlif et al 2020 An Optimal Algorithm For A Fuzzy Transportation Problem (Jurnal of Southwest Jiaotong University vol 55) pp 1-11

[4] A. Kumar and K. Amarpreet 2011 Application of classical transportation methods for solving fuzzy transportation problems (Journal of Transportation Systems Engineering and Information Technology vol 11 no. 5) pp 6880
[5] B. Stanojevic S et al 2019 Solution approach to a special class of full fuzzy linear programming problems (Procedia Computer Science, vol 162) pp 260-266

[6] A. Baykasoglu and K. Subulan 2017 Constrained fuzzy arithmetic approach to fuzzy transportation problems with fuzzy decision variables (Expert Systems with Applications, vol 81) pp 193-222

[7] R. K. Saini, A. Sangal and O. Prakash 2018 Fuzzy transportation problem with generalized triangular-trapezoidal fuzzy number. In: PANT, M., RAY, K., SHARMA, T., RAWAT, S., and BANDYOPADHYAY, A. (eds.) (Soft Computing: Theories and Applications. Advances in Intelligent Systems and Computing vol 583) pp 723-734

[8] S. P. Modal and M. Mandal 2017 Pentagonal fuzzy number, its properties and application in fuzzy equation (Future Computing and Informatics Journal vol 2 no 2) pp 110-117

[9] B. Amaliah et al 2016 Metode Max Min Vogel'S Approximation Method untuk Menemukan Biaya Minimal pada Permasalahan Transportasi (Proceedings of the National Seminar on Mathematics vol 24) pp 1-8

[10] S. Singh et al 2012 Optimization and analysis of some variants through Vogel's approximation method (VAM) (IOSR Journal of Engineering vol 9 no 2) pp 20-30 